\title{
Aldehyde Oxidase (AO) in the Root Nodules of Lupinus albus and Medicago truncatula: Identification of AO in Meristematic and Infection Zones
}

\author{
Elena Fedorova,, ${ }^{1,2}$ Francisco J. Redondo, ${ }^{1}$ Tomokazu Koshiba, ${ }^{3}$ José J. Pueyo, ${ }^{1}$ M. Rosario de Felipe, ${ }^{1}$ \\ and M. Mercedes Lucas ${ }^{1}$ \\ ${ }^{1}$ Departamento de Fisiología y Bioquímica Vegetal, Centro de Ciencias Medioambientales, CSIC, Serrano 115-bis, E-28006 \\ Madrid, Spain; ${ }^{2}$ K. A. Timiryazev Institute of Plant Physiology RAS, Botanicheskaya 35, Moscow, 127276, Russia; \\ ${ }^{3}$ Department of Biological Sciences, Tokyo Metropolitan University, Hachioji-shi, Tokyo 192-0397, Japan
}

Submitted 2 June 2004. Accepted 6 January 2005.

\begin{abstract}
Phytohormones are involved in the organogenesis of legume root nodules. The source of the auxin indole-3-acetic acid (IAA) in nodules has not been clearly determined. We studied the enzyme aldehyde oxidase (AO; EC 1.2.3.1), that catalyzes the last step of IAA biosynthesis in plants, in the nodules of Lupinus albus and Medicago truncatula. Primordia and young lupin nodules and mature $M$. truncatula nodules showed AO activity bands after native polyacrylamide gel electrophoresis. Gel activity analyses using indole3-aldehyde as substrate indicated that the nodules of white lupin and $M$. truncatula have the capability to synthesize IAA via the indole-3-pyruvic acid pathway. Immunolocalization and in situ hybridization experiments revealed that AO is preferentially expressed in the meristematic and the invasion zones in Medicago nodules and in the lateral meristematic zone of Lupinus nodules. High IAA immunolabeling was also detected in the meristematic and invasion zones. Low expression levels and no AO activity were detected in lupin $\mathrm{Fix}^{-}$nodules that displayed restricted growth and early senescence. We propose that local synthesis of IAA in the root nodule meristem and modulation of $\mathrm{AO}$ expression and activity are involved in regulation of nodule development.
\end{abstract}

Additional keywords: ABA, Bradyrhizobium, immunofluorescence, Mesorhizobium loti.

The association of leguminous plants and bacteria from the Rhizobiaceae family results in a symbiosis that allows the conversion of atmospheric nitrogen to ammonia in a new specific organ, the root nodule. Nodule development requires integrated processes, both in the host cell and in the microsymbiont (Stougaard 2000). In the early stages of infection, the rhizobial nodulation signal molecules known as Nod factors are induced in response to the secretion of flavonoids by the plant, representing the primary morphogenetic signal for nodulation (Long 1996). Phytohormones are considered to be secondary signals in the developmental program of the root nodule (Fang and Hirsch 1998; Hirsch 1992). Coregulation of several enod genes by Nod factors and plant hormones suggests that Nod factors and phytohormones may act synergistically or via the convergence of their signaling pathways during nodule development (Schultze and Kondorosi 1998). Flavonoids are poten-

Corresponding author: M. Mercedes Lucas; E-mail: mlucas@ccma.csic.es tial candidates for endogenous inhibitors of auxin transport in the early stages of nodule initiation (Hirsch 1992). It has been shown that flavonoids induced in white clover cells undergoing nodule organogenesis can regulate peroxidase-mediated auxin breakdown (Mathesius 2001). Reduction in auxin transport and imbalance in phytohormonal levels cause the stimulation of root cell divisions and subsequent formation of root nodule primordia. Rhizobia themselves or Nod factors lead to local inhibition of acropetal auxin transport (Boot et al. 1999; Hirsch et al. 1989; Mathesius et al. 1998). Studies of auxin import carrier AUX1-like genes in Medicago truncatula indicate that auxin is required in early nodule development (de Billy et al. 2001).

Nodule formation requires high auxin levels to initiate the process of cell division and the establishment of the primordium. Expression of the auxin-responsive GH3 gene is high in dividing cells of primordia but decreases during later stages of development and differentiation (Mathesius et al. 1998).

Phytohormones exert a temporal and local control on the cell cycle and affect the transcription of cell-cycle genes or the activity of the cyclin-dependent kinases during nodule development. It has been shown that mitotic B-type cyclins Cyc1 and $\mathrm{Cyc} 4$ are induced by auxin and cytokinin in the meristematic tissue of yellow lupin (Jelenska et al. 2000). In root nodules of $M$. truncatula, cyclin A2, implicated in cell cycle activation, is up-regulated by auxins (Roudier et al. 2003). Auxins can also be involved in the control of nodule number (Varma et al. 2003).

The regulation of the early steps of nodule organogenesis by auxins, cytokinins, and ethylene has been studied extensively (Cooper and Long 1994; Ferguson and Mathesius 2003; Heidstra et al. 1997; Lohar et al. 2004; Mathesius et al. 1998, 2000; Oldroyd 2001). Information concerning the action of auxins has been obtained in experiments that involve the application of exogenous phytohormones or the synthetic auxin transport inhibitor 1- $N$-naphthylphthalamic acid (NPA) to legume roots. The observation that NPA elicits the formation of nodulelike structures and the expression of early nodulin genes (Hirsch 1992; Hirsch et al. 1989) and the fact that rhizobia (via the Nod factors) produce an accumulation of IAA (Mathesius et al. 1998) and a local reduction of auxin transport capacity prior to nodule primordium development (Boot et al. 1999) suggest a role for auxin in the earliest stages of nodule formation. As early as 1992, the study of gene expression or protein patterns relative to the hormone biosynthetic pathways was proposed as the best way to analyze the role of plant hormones 
in nodulation (Hirsch 1992). However, to date, little is known about the auxin biosynthesis pathways and the factors that regulate auxin levels in vivo during root nodule development.

It has been shown that plants can synthesize indole-3-acetic acid (IAA) from tryptophan (Trp), and both Trp-dependent and Trp-independent pathways have been proposed for IAA synthesis from Trp precursors (Bartel 1997). The Trp-dependent indole-3-pyruvic acid pathway includes aldehyde oxidase (AO), which converts indole-3-acetaldehyde to IAA (Bartel 1997; Normanly and Bartel 1999).

The study of AO in maize (Koshiba et al. 1996; Sekimoto et al. 1997) and in the auxin-overproducing Arabidopsis superoot 1 (sur 1) mutant (Seo et al. 1998) confirms its role in IAA biosynthesis. In Arabidopsis, one AO isoform, AO $\alpha$, is able to oxidize indole- 3 aldehyde as well as indole-3-acetaldehyde, a precursor of IAA (Akaba et al. 1999) and shows a higher substrate preference for these aldehydes than the other AO isoforms from Arabidopsis seedlings. This activity was significantly higher in Arabidopsis superoot 1 than in wild-type Arabidopsis plants (Sekimoto et al. 1997; Seo et al. 1998). AO is also involved in abcisic acid (ABA) biosynthesis (Seo and Koshiba 2002). AAO3 gene product catalyzes the final step in ABA synthesis in leaves (Seo et al. 2000b) and seeds (GonzálezGuzmán et al. 2004). AO isoforms that can efficiently oxidize abcisic aldehyde have been described in Arabidopsis rosette leaves (Seo et al. 2000a), in barley roots (Omarov et al. 2003),

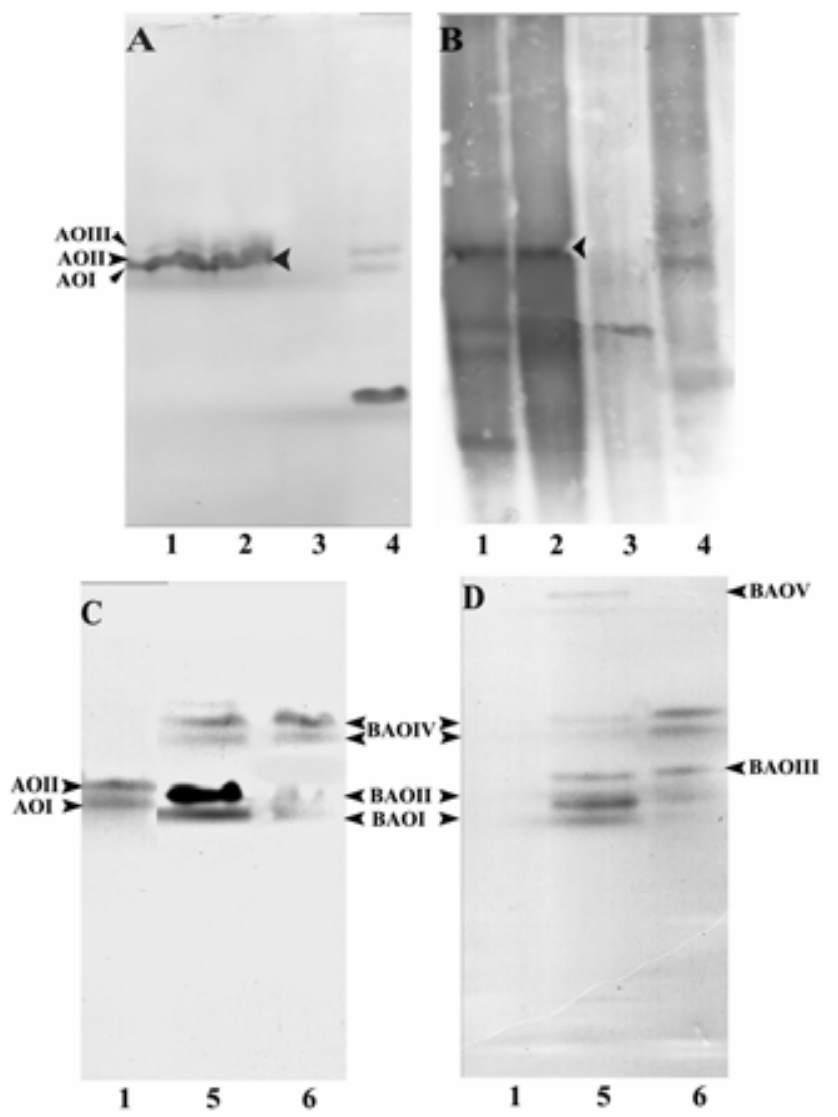

Fig. 1. Zymograms and immunoblot after native polyacrylamide gel electrophoresis of protein extracts from nodules of Lupinus albus and Medicago truncatula and Bradyrhizobium sp. (Lupinus) cell suspensions. $\mathbf{A}$, and $\mathbf{C}$, Aldehyde oxidase (AO) activity gels with indole-3-aldehyde as a substrate. B, Immunoblot with AAOlantibody. D, AO activity gel with heptaldehyde as a substrate. Lane 1, L. albus wild-type (wt) nodule (21 days old); lane 2, L. albus wt nodule primordium (16 days old); lane $3, L$. albus Fix $^{-}$nodule (16 days old); lane 4, M. truncatula nodule (21 days old); lane 5, bacteroids isolated from lupin wt nodules; and lane 6, freeliving Bradyrhizobium cells. and in leaves and roots of pea plants (Zdunek-Zastocka et al. 2004).

Little information is available regarding AO localization in plants. The spatial distribution of this enzyme has been studied mainly with activity gels, showing that the enzyme is abundant in the apical region of maize coleoptiles and in the roots of Arabidopsis seedlings (Koshiba et al. 1996; Sekimoto et al. 1997; Seo et al. 1998). Most information about AO comes from studies on nonleguminous plants or nonnodulated legumes (Miyata et al. 1981; Zdunek and Lips 2001; Zdnuek-Zastocka et al. 2004).

In the present work, we have studied the presence of AO in primordia and nodules of Lupinus albus and in nodules of Medicago truncatula, which represent two legume nodule types with different structure and developmental patterns. A potential role for $\mathrm{AO}$ in legume nodule organogenesis is discussed.

\section{RESULTS}

\section{AO isoforms.}

To analyze the presence of plant and bacterial AO isoforms in legume nodules, cytosol extracts from L. albus and M. truncatula nodules, bacteroids, inoculated and noninoculated roots of L. albus, and free-living bacteria were subjected to native polyacrylamide gel electrophoresis (PAGE) and were analyzed for AO activity. Figure 1 shows the results when indole-3-aldehyde (IAld) (an analog of indole-3-acetaldehyde) and heptaldehyde were used as substrates.

The analysis of the cytosol of lupin nodules induced by Bradyrhizobium sp. (Lupinus) (hereafter referred to as "wt nodules") showed two strongly stained bands, AOI and AOII, as well as a very faint band, AOIII, when IAld was used (Fig. 1A). No differences were found in the $\mathrm{AO}$ band pattern between primordia and mature nodules of lupin. Mesorhizobium loti is an incompatible strain that induces the formation of early-senescent Fix ${ }^{-}$nodules (González-Sama et al. 2004). No active AO bands were detected in Mesorhizobium loti-induced Fix lupin nodules (Fig. 1A). No AO bands were observed in the cytosolic protein extracts of lupin wt nodules when heptaldehyde was used as a substrate (Fig. 1D).

Bacteroids were isolated from lupin nodules in order to test for $\mathrm{AO}$ activity in the microsymbiont and to confirm that nodule extracts were free of bacterial AO activity. The AO zymogram obtained from Bradyrhizobium bacteroids (Fig. 1C and D) was different from the pattern described above for cytosol extracts from nitrogen-fixing lupin nodules. Four bands, BAOI, BAOII, and a double BAOIV band, with clear differences in their electrophoretic mobility, were developed with IAld. The band pattern obtained with heptaldehyde as a substrate (Fig.1D) included new active bands (BAOIII, BAOV). The intensity of the bands in free-living Bradyrhizobium extracts differed from that observed in bacteroid extracts (Fig. $1 \mathrm{C}$ and $\mathrm{D}$ ), thus suggesting that the affinity of the AO isoenzymes for the substrates might be related to the symbiotic stage of the bacteria. No AO activity bands were detected in protein extracts from inoculated and noninoculated roots of $L$. albus collected five days after inoculation, with any of the substrates used (data not shown).

Active AO that might be involved in IAA biosynthesis were also found in the cytosol of $M$. truncatula nodule cells. Nodule extracts exhibited three AO activity bands, two of which had similar electrophoretic mobility to lupin nodule AOs, while the third band showed faster mobility and stronger IAld staining (Fig. 1A). Heptaldehyde was not oxidized by AO from $M$. truncatula nodules (data not shown).

Anti-AO antibodies raised against $A$. thaliana AAO1 and AAO2 were used to detect antigens in L. albus and M. trunca- 
tula nodules. Both antibodies cross-reacted similarly with nodule AO. Figure 1B shows the results when AAO1 antibody was used. Immunoblot analysis after native PAGE revealed several immunoreactive bands, some of which corresponded to $\mathrm{AO}$ activity bands. Additional bands could be inactive isoforms or related polypeptides immunolabeled by the antibodies, as previously described in Arabidopsis (Akaba et al. 1999). It is noteworthy that the extract from Mesorhizobium loti-elicited lupin nodules showed an intensely immunolabeled inactive band that was not observed in nitrogen-fixing lupin nodules. Immunoblot after sodium dodecyl sulfate-PAGE revealed that both antibodies immunorecognized polypeptides of approximately 140 and $145 \mathrm{kDa}$ in protein extracts of lupin wt nodules and $M$. truncatula nodules (data not shown). In $A$. thaliana, polypeptides of 150 and $145 \mathrm{kDa}$ have been found (Akaba et al. 1999). Polypeptides ranging from 140 to $160 \mathrm{kDa}$ have been identified as subunits of $\mathrm{AO}$ isoforms in several plant species (Omarov et al. 2003; Zdnunek-Zastocka et al. 2004).

\section{Localization of AO, ABA, and IAA in root nodules.}

Nodules of M. truncatula and L. albus represent two different types of nodule structure and development, indeterminate and lupinoid, respectively. The alfalfa nodule has a persistent apical meristem (zone I) active for six to eight weeks and a clear zonation of the infected zone (Vasse et al. 1990). Infection takes place in zone II, in which bacteria are released from infection threads into the host cell cytoplasm. In zone III, infected cells grow and become host to developing bacteroids with high nitrogen-fixing activity. The senescence zone IV is located in the basal part of the nodule (Vasse et al. 1990).

The nodule of white lupin does not have the characteristic zonation of the elongated indeterminate nodules as does the Medicago nodule. The primordial white lupin nodule ( 7 to 10 days old) consists mainly of meristematic cells, situated in the central part, surrounded by several layers of cortical cells. In young nitrogen-fixing nodules ( 21 days old), the central infection zone is surrounded by the nodule cortex that contains the peripheral vascular elements. Several layers of young cells with high proliferative activity are situated in the periphery of infected tissue (Fig. 2A and B). In root nodules of yellow lupin, these cell layers were referred to as the lateral meristematic zone (LMZ) (Jelenska et al. 2000). The central infected tissue surrounded by the LMZ contains mature infected cells with nitrogen-fixing bacteroids.

We studied $L$. albus nodules elicited by two different strains, Bradyrhizobium sp. (Lupinus) ISLU16 and Mesorhizobium loti NZP2037. Inoculation with Bradyrhizobium strain ISLU16 leads to the formation of active nitrogen-fixing nodules (Fig. 2A). Mesorhizobium loti NZP2037 is able to nodulate L. albus roots (González-Sama et al. 2004), but the resulting symbiosis is not effective, and small, white Fix ${ }^{-}$nodules are formed (Fig. $2 \mathrm{C}$ and D). The meristematic activity of $\mathrm{Fix}^{-}$nodules seized within 10 days, and 16-day-old nodules did not have a LMZ. The microsymbiont underwent premature senescence and complete lysis within three weeks (Fig. 2D).

$\mathrm{AO}$ immunolocalization with either AAO1 or AAO2 antibodies gave similar spatial patterns. In $M$. truncatula nodules, the strongest fluorescent signal was observed in the apical part, in the cytosol of meristematic and zone II cells (Fig. 3A, B, C, and D). Signal was also detected in the pericycle cells of the vascular bundles (data not shown). Mature infected cells displayed low levels of immunofluorescence, showing a gradient over the interzone II/III (Fig. 3A and D).

In lupin wt nodules induced by Bradyrhizobium strain ISLU16, the protein was relatively overexpressed in the LMZ (Fig. 3E, F, and G). In young nodules, fluorescence was located in a circle around the infected zone, which corresponds to the dividing infected and noninfected young cells. In mature lupin wt nodules (30 days, Fig. 3I) and in the central part of $M$. truncatula nodules (zone III, Fig. 3A and D), the signal for AO protein was uniformly present over the cytosol of nodule cells with a slightly higher intensity than the background fluorescence (Fig. 3J). In 10-day-old lupin nodules elicited by Mesorhizobium loti, in which both the infected cells and the noninfected cells surrounding them were still actively dividing (Fig. 2C), immunolabeling was detected in the dividing cell (not shown). In 16-day-old lupin $\mathrm{Fix}^{-}$nodules elicited by Mesorhizobium loti, the pattern of AO immunolocalization was different from that described for young wt nodules. Fix ${ }^{-}$nodules did not have the LMZ, and the level of fluorescence was low, similar to that observed in 30-day-old mature wt nodules (data not shown).
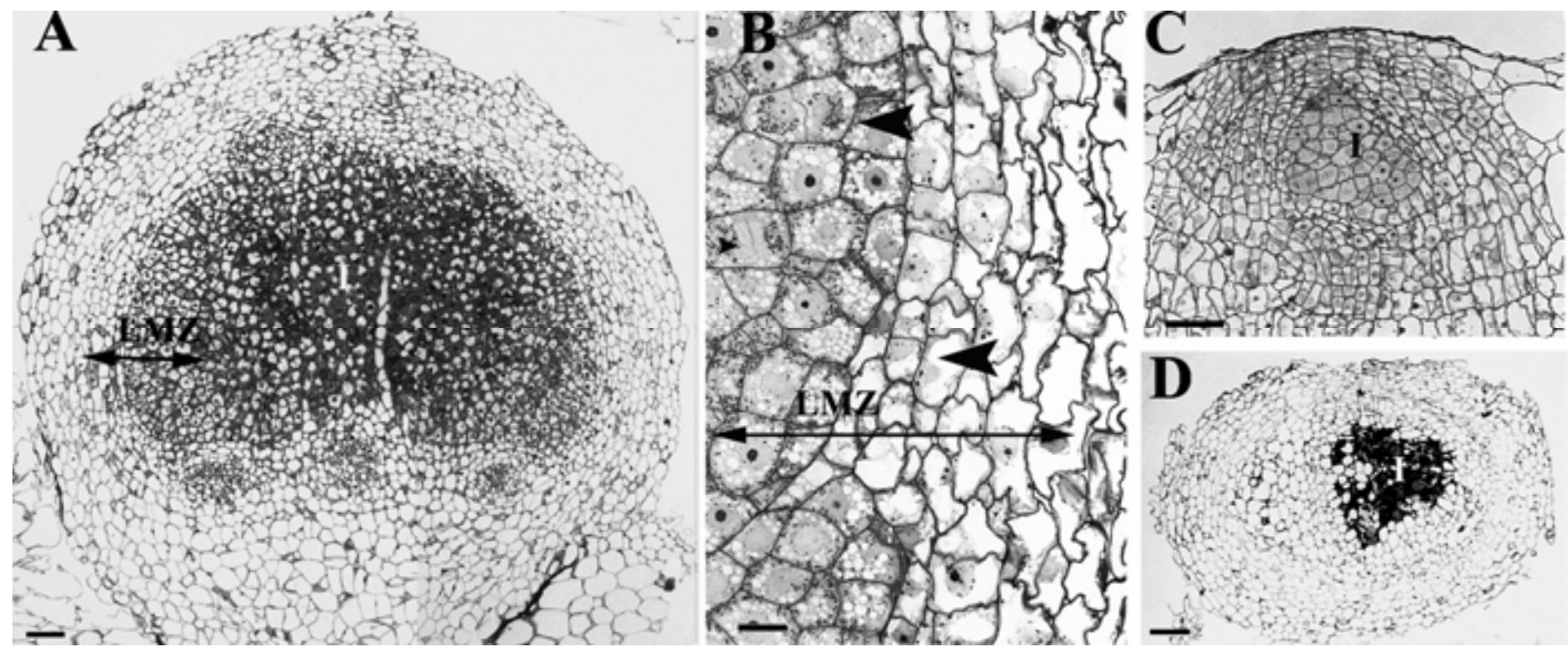

Fig. 2. Light micrographs showing the structure of a Lupinus albus root nodule after staining with methylene blue. A, A 21-day-old lupin nodule elicited by Bradyrhizobium sp. (Lupinus) showing the central infected cells (I) and the lateral meristematic zone (LMZ). Bar $=100 \mu \mathrm{m}$. B, Magnification of the previous image showing LMZ diving cells (arrows). Bar $=16 \mu \mathrm{m}$. C, A 10-day-old nodule elicited by Mesorhizobium loti showing the central zone containing infected cells $(\mathrm{I})$. Bar $=50 \mu \mathrm{m}$. D, A 21-day-old nodule elicited by $M$. loti. Note the infected zone consisting of cells undergoing premature senescence. Bar $=100 \mu \mathrm{m}$. 
To confirm the immunofluorescence pattern, we performed analyses with purified antibodies. AAO1 antibody was eluted from a Western blot membrane (discussed below) and was employed to localize AO in $M$. truncatula nodules. The pattern was identical to that described above with a strong fluorescent signal in the apical part of the nodule (data not shown).

We analyzed the presence of two putative products of $\mathrm{AO}$ activity, ABA and IAA, in nodule tissues. The final step of
$\mathrm{ABA}$ biosynthesis is catalyzed by $\mathrm{AO}$, and one $\mathrm{AO}$ isoform has been associated mainly with ABA synthesis in root-tip dividing cells and in lateral root primordia of $A$. thaliana (Koiwai et al. 2004; Seo et al. 2000a). In order to clarify the topology of ABA localization, we performed ABA immunolocalization using anti-ABA antibodies. ABA localization did not show any specific site of overexpression. The low level of immunofluorescent signal was uniformly present over all tissues of $\mathrm{Lu}$ -
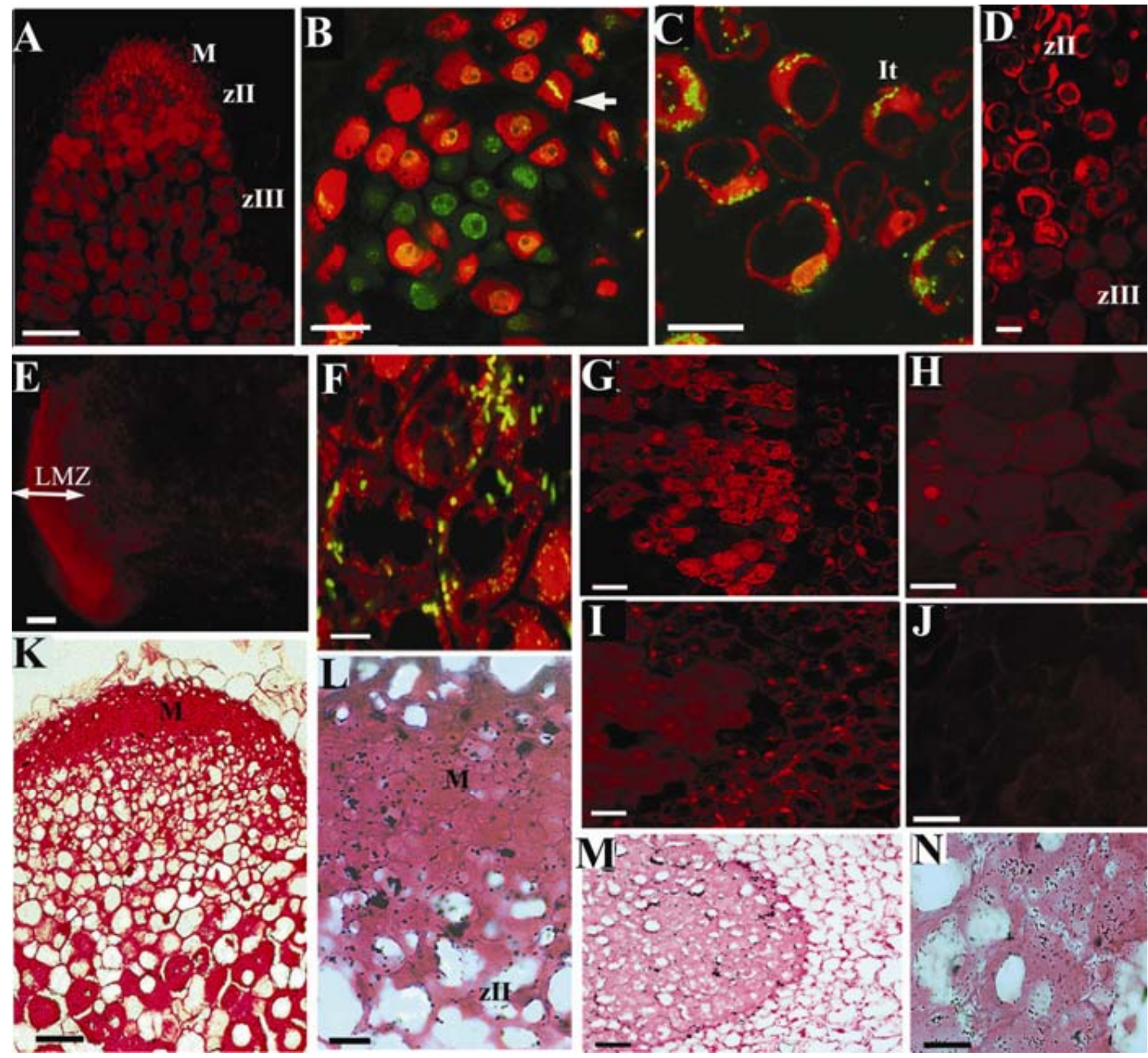

Fig. 3. Localization and expression of aldehyde oxidase (AO) and localization of abcisic acid in nodules of Medicago truncatula and Lupinus albus. A through $\mathbf{D}, \mathbf{K}$, and $\mathbf{L}$, Sections of $M$. truncatula nodules. $\mathbf{E}$ through $\mathbf{J}, \mathbf{M}$, and $\mathbf{N}$, Sections of $L$. albus nodules. A, and $\mathbf{E}$, Fluorescence microscopy with AAO2 and AAO1 antibodies, respectively. B through D, F, G and I, Laser confocal microscopy with AAO1 antibody. A, Micrograph showing immnolocalization of AO. Note the strong fluorescent signal in the meristem $(\mathrm{M})$ and zone II. Bar $=50 \mu \mathrm{m}$. B, Detail of the meristematic zone, a metaphase can be observed (arrow). Nuclei contrasted with SYTOX are visualized in green. Bar $=20 \mu \mathrm{m}$. C, Infected zone II in which bacteria are being released from the infection thread (it) into the cell cytosol. Cytosol shows AO immunolabeling in red, and green bacteria are contrasted with SYTOX. Bar $=10 \mu \mathrm{m}$. D, Micrograph showing AO localization in zone II, interzone II/III, and zone III. Bar $=10 \mu \mathrm{m}$. E, Strong fluorescent signal in the cells of the lateral meristematic zone (LMZ). Bar $=100 \mu \mathrm{m}$. F, Detail of infected cells of the LMZ showing strong immunolabeling. Bar $=10 \mu \mathrm{m}$. G, Localization of AO in the lateral part of a 16-day-old wild-type (wt) primordium showing strong AO immunostaining in the cytosol of several infected cell layers. Bar $=50 \mu \mathrm{m}$. $\mathbf{H}$, Lateral part of a 16-day-old wt primordium showing infected cells labeled with anti-abcisic acid antiserum. Bar $=16 \mu \mathrm{m}$. I, Lateral part of a 30-day-old wt nodule with low immunolabeling in mature infected cells. Bar $=50 \mu \mathrm{m}$. $\mathbf{J}$, Control section in which the primary antibody was omitted. Bar $=16 \mu \mathrm{m} . \mathbf{K}, \mathrm{AO}$ mRNA localized in a longitudinal section of a $M$. truncatula nodule by in situ hibridization. Silver-black spots denote transcript accumulation. Bar $=16 \mu \mathrm{m}$. $\mathbf{L}$, Detail of the previous image. Bar $=50 \mu \mathrm{m}$. M, AO mRNA localization in the lateral part of 21-day-old wt lupin nodule. Silver-black spots denote transcript accumulation. Bar $=16 \mu \mathrm{m}$. N, Detail of the previous image. Bar $=50 \mu \mathrm{m}$ 
pinus (Fig. 3H) and Medicago (data not shown) root nodules. Intense fluorescence was observed on the nuclei and the periphery of infected cells, due to immunolabeling of the numerous plastids and to labeling of the cell wall regions. ABA immunogold localization on nuclei and chloroplasts of stressed pea and lavender plants has been described by Welbaum and associates (1997) and Pastor and associates (1999), respectively. The immunolocalization pattern of ABA did not display any kind of gradient over the nodule tissue as described above for the immunolabeling of AO protein.

Immunohistochemical detection of IAA was carried out in nodules fixed with EDAC, a reagent that cross-links the carboxyl group of free IAA to structural proteins while preserving the antigenicity of IAA (Aloni et al. 2003; Thomas et al. 2002). The strongest immunofluorescence signal was detected in the apical part of M. truncatula nodules (Fig. 4A), including the meristem, zone II, and first cells layer of zone III, as well as in the LMZ of lupin nodules (not shown). Nuclei were clearly immunolabeled and the nucleoplasm showed stronger signal than the nucleoli (Fig. 4B and C). A weak cytosol labeling, although distinguishable from background autofluorescence (Fig. 4C), was also observed in all cells, except the empty, possibly dead cells of the basal part of the nodule, in zone IV (Fig. 4D). It is noteworthy that the nuclear signal was mainly present in apical cells of $M$. truncatula nodules and in pericycle cells but it could not be observed in mature differentiated cells. Nuclear localization of IAA has been reported in root meristematic cells (Ohmiya et al. 1990) and also in cells within the morphogenic zone but not in tissues in which any cell division activity was soon to be expected, in sunflower immature zygotic embryo explants (Thomas et al. 2002). In
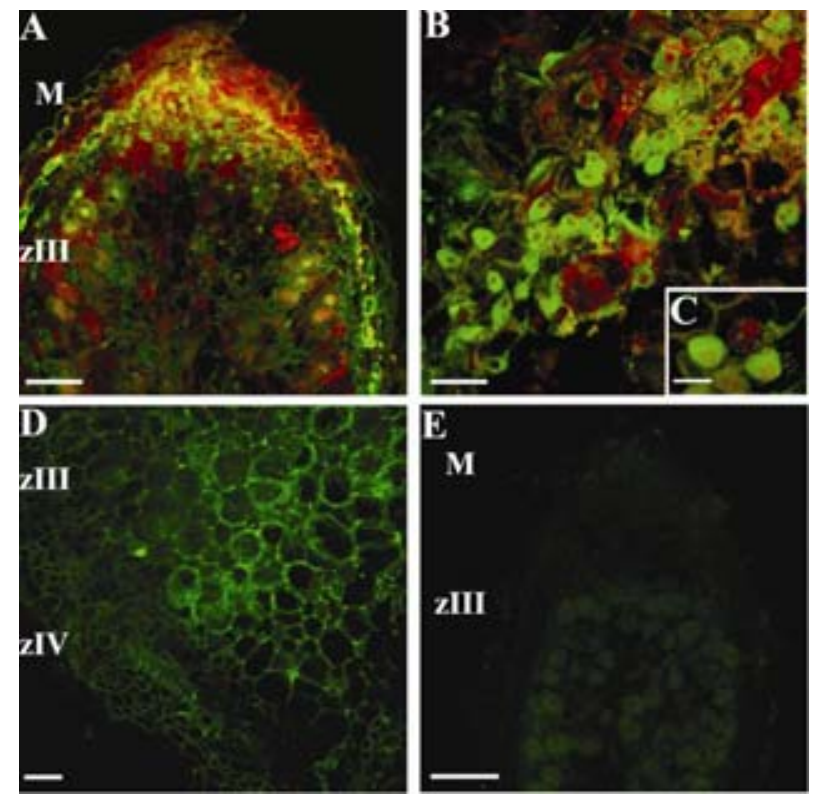

Fig. 4. Immunolocalization of indole-3-acetic acid (IAA) in nodules of Medicago truncatula. A, Micrograph of a nodule section counterstained in red with propidium iodide (PI), showing immunolocalization of IAA. Note the strong green fluorescent signal in the meristem (M), zone II, and a lateral cell layer, corresponding to the pericycle in the vascular bundle. The yellow color is due to the addition of red and green fluorescences. Bar $=50 \mu \mathrm{m}$. B, Meristematic zone showing strong immunolabeling of nucleoplasm. Nucleoli in red due to PI staining. Bar $=20 \mu \mathrm{m}$. C, High magnification micrograph of meristematic cells. Bar $=5 \mu \mathrm{m}$. D, Cells of zones III and IV in a nodule section not counterstained with PI. Note the weak immunolabeling signal in the cytoplasm region closed to the cell walls in mature cells. Empty cells in zone IV do not display the cytosolic signal. Bar $=25 \mu \mathrm{m}$. E, Control section where the primary antibody was omitted. Bar $=50 \mu \mathrm{m}$. nodules, the highest IAA immunolocalization signal was found in the same cell types and nodule zones in which the strongest AO immunofluorescence signal was detected.

\section{$A O$ gene expression.}

Partial cDNA clones were obtained by reverse transcriptasepolymerase chain reaction (RT-PCR) from RNA isolated from L. albus and M. truncatula nodules. Their sequence analysis revealed high homology with other plant $A O$ genes. L. albus and $M$. truncatula $A O$ partial cDNA clones showed 89 and $86 \%$ identity, respectively, with the A. thaliana AAO1 published sequence (Sekimoto et al. 1998). Southern blot experiments suggest the presence of three AO homologs in the $M$. truncatula genome (data not shown).

$A O$ expression was studied with whole-mount radioactive in situ hybridization in 21-day-old L. albus and M. truncatula nodules. A total of 10 to 20 nodules were analyzed per case. A high level of expression was found in the meristem of the $M$. truncatula nodule (Fig. $3 \mathrm{~K}$ and L) and in the lateral meristematic zone of the lupin nodule (Fig. 3M and N). The significant background observed in nodule tissue did not allow us to discriminate the signal on the mature infected cell of lupin and $M$. truncatula nodules. The expression pattern evidenced by in situ hybridization was similar to the immunolocalization pattern of AO protein. The distribution of silver granules in sense probe-labeled slides revealed a nonspecific diffuse background signal uniformly present in all cells (data not shown).

Specific primers were used to analyze $A O$ expression in lupin primordia, nodules, and Mesorhizobium loti-elicited Fix ${ }^{-}$ nodules (Fig. 5). The highest expression level was observed in primordia and the lowest in $\mathrm{Fix}^{-}$primordia, this being in agreement with the AO activity detected in gel and immunolocalization analyses.

\section{DISCUSSION}

Phytohormones such as cytokinins and auxins are most likely involved in nodule initiation and development, because they are necessary for activation and completion of the cell cycle. High concentration of phytohormones can also modulate the sink-source relationship of developing primordia with the whole plant and favor the quick growth of nodules. This strategy, used by Agrobacterium tumefaciens (Zhu et al. 2000), is responsible for proliferation of transformed plant cells in tumors.

The origin of IAA in legume nodules is still not clear. It is known that the young root nodule has increased concentrations of auxins, and this high level of auxins has been attributed mostly to polar transport (Fedorova et al. 2000; Kawaguchi

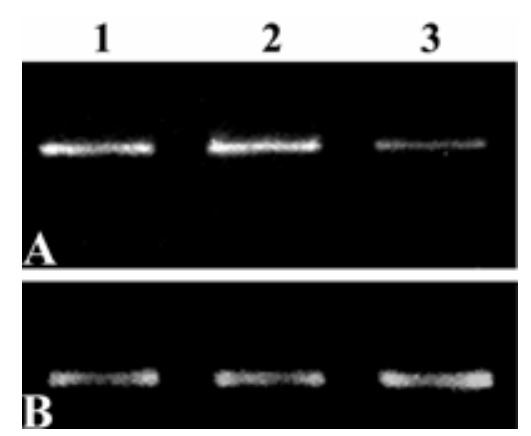

Fig. 5. Aldehyde oxidase (AO) expression. A, Reverse transcriptasepolymerase chain reaction analysis of $\mathrm{AO}$ expression. B, Ubiquitin expression as a control. Lane 1, Lupinus albus wild-type (wt) nodule (21 days old); lane 2, L. albus wt nodule primordium (16 days old); and lane 3, L. albus $\mathrm{Fix}^{-}$nodule (16 days old). 
and Syono 1996). During lateral root and nodule development, genes related to auxin transport are expressed in primordia, particularly in cells derived from the pericycle and, in later stages, in the regions of the developing organs in which vasculature arises (de Billy et al. 2001). On the other hand, it has been suggested that elevated levels of IAA in nodules can be derived from the prokaryotic microsymbiont (Lambrecht et al. 2000). It has also been shown that inoculation with Bradyrhizobium mutants with low IAA production reduced the number of root nodules in soybean, and the involvement of IAA produced by the microsymbiont has been suggested (Fukuhara et al. 1994).

To further investigate the role of auxins in nitrogen-fixing symbioses, we studied the enzyme AO, involved in auxin biosynthesis via the indole-3-pyruvic acid pathway. AO catalyzes the oxidation of indole-3-acetaldehyde to form IAA (Koshiba et al. 1996). Our results show that, in legume root nodules, both the plant cell and the bacteroid have active AO that might play distinct roles in the nodule. The different AO activityband patterns observed in the plant cell cytosol and the microsymbiont clearly indicate that the cytosolic fraction of the nodules was not contaminated with bacterial enzyme. Moreover, immunolocalization experiments showed that AO mostly accumulates in the meristematic cells of the Medicago nodule, devoid of bacteria, thus suggesting that the AO activity in nodules can be mainly attributed to the plant symbiont and not to the prokaryote. Isolated bacteroids and free-living bacteria displayed similar activity-band patterns. The relative abundance of isoenzymes and their substrate preference could be related to the symbiotic stage of the rhizobia. It is interesting to note that heptaldehyde acted as a good substrate for bacterial AO only. This could be an indication that rhizobial AO might be involved in metabolic pathways in the nodule other than IAA biosynthesis. Heptaldehyde may be used as a marker to discriminate bacterial AO isoenzymes from plant $\mathrm{AO}$ isoenzymes in the nodule. The fact that no activity was detected in either inoculated or noninoculated roots could be due to the dependence of the root system on basipetal auxin transport or to the contribution of other pathways of auxin biosynthesis to the root system auxin pool.

Existing data indicate that indole-3-acetic acid synthesis can be activated in regions other than the shoot apex (Ljung et al. 2002; Normanly and Bartel 1999). According to Ljung and associates (2002), all parts of the plant can potentially act as sites for IAA biosynthesis, and root tissue has a high capacity to synthesize IAA. In nodules, our results showed that $\mathrm{AO}$ expression levels did not correlate with ABA immunolocalization, which was uniform over the nodule tissues. Differently, the highest IAA levels were detected in the nodule zones, in which AO protein and mRNA accumulated preferentially. The lack of correlation between the $\mathrm{AO}$ and $\mathrm{ABA}$ location and the spatial correlation between $\mathrm{AO}$ and IAA immunolocalization suggest that AO might be mainly involved in local IAA synthesis.

However, we cannot exclude the possibility that nodule AO is also active in ABA biosynthesis or in aldehyde detoxification. The occurrence of different IAA biosynthesis pathways, such as the nitrilase pathway, cannot be excluded either. So far, there is no evidence of the involvement of $\mathrm{AO}$ in plant developmental processes, however the involvement of an AO isoenzyme in the synthesis of indole-3-acetic acid in young pea leaves has been suggested recently (Zdunek-Zastocka et al. 2004).

Medicago truncatula and L. albus nodules have different structure and development. However, the sites of expression of AO during the development of both types of nodules can be considered equivalent. AO was highly expressed in the meristem and the infection zone of the nodules. In M. truncatula, these locations correspond to zones I and II, respectively. In lupin nodules, AO was located in the lateral meristematic zone, which is composed of noninfected cells and infected cells (with a low number of bacteria) that retain their ability to divide. For this reason, the lateral meristematic zone is comparable to zones I and II in medical barrel nodules. Lupin $\mathrm{Fix}^{-}$nodules with restricted growth and early senescence displayed low levels of AO protein, no indole-3-aldehyde-oxidizing activity, and low gene expression. It is well known that the size of Fix nodules is always smaller than that of nodules elicited by $\mathrm{Fix}^{+}$ strains. Meristematic activity ceases early and, consequently, their growth is usually limited (Kiers et al. 2003; Vasse et al. 1990). It is possible that the host plant may play an active role in the regulation of nodule auxin synthesis and be involved in the regulation of nodule meristem growth and development. It is known that the ratio of cytokinin to auxin levels is important in the development and maintenance of the nodule (Ferguson and Mathesius 2003; Hirsch et al. 1997). Localized IAA synthesis could provide a fine regulation mechanism of the auxin/ cytokinin ratio.

Phytohormones, mostly auxins and cytokinins, endogenously exert a temporal and local control on the cell cycle (Stals and Inze 2001). Mitogen-activated protein kinase (MAPK) activation by auxin treatment suggests that MAPK cascades might mediate cellular responses to auxin (DeLong et al. 2002). Mitotic B-type cyclins in yellow lupin nodules (Jelenska et al. 2000) and A2-type cyclins in alfalfa nodule meristems (Roudier et al. 2003) are auxin-upregulated. It seems likely that AO has a role in the regulation of IAA biosynthesis, and IAA can play a role in nodule organogenesis, a process that is necessarily linked to a fine regulation of the cell cycle. We cannot ascertain whether high AO expression in the nodule meristematic tissue is the cause of its high proliferation activity or a consequence of it. The modulation of auxin synthesis in the root nodule meristem may allow the plant to exert control over the growth of effective root nodules and suppress noneffective symbioses. It is possible that self-regulation of nodule development is achieved by local control of auxin synthesis via the indole-3piruvic acid pathway, by means of either $\mathrm{AO}$ expression, activity in the root nodule meristem, or both.

\section{MATERIALS AND METHODS}

Plant material, growth conditions, and rhizobial strains.

Seeds of Lupinus albus L. cv. Multolupa and M. truncatula $\mathrm{R} 108$ were surface-sterilized in $1 \% \mathrm{HgCl}_{2}$ with gentle shaking, were rinsed several times with distilled water, and were allowed to imbibe water for $2 \mathrm{~h}$. Seeds were sown in pots filled with vermiculite for lupin plants and sand/vermiculite (1:2) for barrel medic. Three days after sowing, lupin seedlings were separately inoculated with suspensions of Bradyrhizobium sp. (Lupinus) ISLU16 or with Mesorhizobium loti NZP2037 (González-Sama et al. 2004). M. truncatula was inoculated with Sinorhizobium meliloti 41.

Bacteria were grown at $28^{\circ} \mathrm{C}$ with shaking in a yeast extractmannitol liquid medium (Vincent 1970). Plants were grown in a growth chamber under controlled conditions consisting of a 16-h light photoperiod, $60 \%$ relative humidity, and temperature of $25^{\circ} \mathrm{C}$ day and $15^{\circ} \mathrm{C}$ night and were irrigated with nitrogen-free nutrient solution (Hoagland and Arnon 1938).

Inoculated and noninoculated roots were collected 12 days after sowing. Lupin primordia, young nodules, and mature nodules were collected 16, 21, and 30 days after sowing, respecttively. Medicago nodules were collected 21 days after sowing.

\section{Enzyme extraction.}

Protein extracts were prepared from fresh or from nodules frozen at $-80^{\circ} \mathrm{C}$ that were collected 16 and 21 days after sow- 
ing. Samples ( 1 to $2 \mathrm{~g}$ ) were ground in a mortar with liquid nitrogen. AO extraction buffer (250 mM Tris, $\mathrm{pH} 8.3,10 \mathrm{mM}$ EDTA, $20 \mathrm{mM}$ dithiothreitol, $10 \mathrm{mM}$ reduced glutathione, and Sigma [St. Louis] protease inhibitor cocktail $[1 \mu \mathrm{l} / \mathrm{ml}]$ ) was added to ground samples. A ratio of 1 to $2.5 \mathrm{~g}$ per $1 \mathrm{ml}$ of buffer was used. The homogenized tissue was centrifuged at $27,000 \times g$ and $4^{\circ} \mathrm{C}$ for $15 \mathrm{~min}$. The resulting supernatant was used in subsequent assays.

Protein extracts were also prepared from cultured bacteria. Bacterial culture $(100 \mathrm{ml})$ was centrifuged at $17,000 \times g$ and $4^{\circ} \mathrm{C}$ for $10 \mathrm{~min}$. The pellet was resuspended in $1 \mathrm{ml}$ of $\mathrm{AO}$ extraction buffer, was sonicated five times $(50 \%, 40 \mathrm{~s})$, and was ground in a mortar with liquid nitrogen. Samples were spun at $20,000 \times g$ and $4{ }^{\circ} \mathrm{C}$ for $15 \mathrm{~min}$, and the supernatant was recovered.

The microsymbiont was isolated from nodules according to the following method. Nodules were ground on ice, in a mortar with $50 \mathrm{mM}$ K-phosphate buffer, $\mathrm{pH} 7.5,1 \mathrm{mM}$ dithiothreitol (DTT), and protease inhibitors cocktail (Sigma). A total of 3.5 $\mathrm{g}$ of nodule tissue in $14 \mathrm{ml}$ of buffer $(1: 4 \mathrm{wt} / \mathrm{vol})$ was used. Samples were centrifuged at $400 \times g$ and $4^{\circ} \mathrm{C}$ for $5 \mathrm{~min}$ to remove cell wall debris and nuclei. The supernatant was then further centrifuged at $8,000 \times g$ and $4^{\circ} \mathrm{C}$ for $10 \mathrm{~min}$. The pellet was washed twice in $7 \mathrm{ml}$ of buffer containing $300 \mathrm{mM}$ sucrose and $2 \mathrm{mM} \mathrm{Cl}_{2} \mathrm{Mg}$, and was resuspended in $1 \mathrm{ml}$ of $\mathrm{AO}$ extraction buffer. After sonication, the bacteroid fraction was ground in a mortar with liquid nitrogen and was extracted as above.

\section{AO activity.}

Proteins were subjected to native PAGE in $7.5 \%$ acrylamide gels in a Laemmli buffer system. Each lane was loaded with $800 \mu \mathrm{g}$ of nodule protein, $900 \mu \mathrm{g}$ of root protein, $120 \mu \mathrm{g}$ of bacteroid protein, or $800 \mu \mathrm{g}$ of bacterial protein. In-gel AO activity was developed as described previously (Zdunek and Lips 2001), in a mixture containing 0.1 M TRIS-HCl, pH 7.5, $1 \mathrm{mM}$ MTT (3[4,5-dimethylthiazol-2-yl]-2,5-diphenyltetrazolium-bromide; Sigma), $0.1 \mathrm{mM}$ phenazine metosulphate (Sigma), and $1 \mathrm{mM}$ indole-3-aldehyde (Aldrich, St. Quentin, France) or heptaldehyde (Aldrich) as substrates. Symmetrically loaded gels were cut in half and were used either for activity analysis or immunological analysis. Experiments were repeated at least three times.

\section{Immunoblot analysis.}

Proteins were transferred onto a nitrocellulose membrane and were visualized using two polyclonal rabbit antibodies (AAO1, AAO2) raised against $A$. thaliana $30-\mathrm{kDa}$ AAO1 and AAO2 polypeptides (Akaba et al. 1999). The anti-AAO1 antibody specifically reacts with isoform $\mathrm{AO} \alpha$ (Seo et al. 2000a), and the anti-AAO2 antibody specifically recognizes $\mathrm{AO} \gamma$ in Arabidopsis seedlings (Akaba et al. 1999), as shown by immunoprecipitation. $\mathrm{AO} \alpha$ and $\mathrm{AO} \gamma$ are not related to ABA synthesis. Both primary antibodies were used at 1:4,000 dilution. Alkaline-phosphatase-conjugated goat anti-rabbit IgG (Sigma) was used as secondary antibody at 1:20,000 dilution. The reaction was detected by a colorimetric reaction (NBT/BCIP; Sigma) according to the standard protocol.

\section{Immunolocalization.}

Indirect immunofluorescence analysis of $\mathrm{AO}$ was performed with samples fixed for $1 \mathrm{~h}$ in $4 \%$ paraformaldehyde in $50 \mathrm{mM}$ phosphate buffer ( $\mathrm{pH}$ 7.4). Samples were embedded in $8 \%$ agarose, and 50- to $100-\mu \mathrm{m}$ sections were cut with a vibratome. Sections were blocked with $2 \%$ bovine serum albumin (BSA) for $30 \mathrm{~min}$, were incubated with the above polyclonal anti-AO antibodies (1:400) overnight at $4{ }^{\circ} \mathrm{C}$ in phosphate-buffered saline (PBS) containing $0.5 \%$ Triton. Alternatively, a purified
anti-AO antibody was prepared. Bands corresponding to the electroblotted nodule proteins of 140 and $145 \mathrm{kDa}$ were dissected from the membrane, and the antibody was eluted from the nitrocellulose strips with PBS-glycine buffer, $\mathrm{pH} 3.5$ (Fedorova et al. 1994). For ABA localization, sections were blocked in 5\% BSA for $1 \mathrm{~h}$ and were further incubated with a polyclonal anti-ABA antibody (Welbaum et al. 1997) $(1: 3,000)$ in PBS containing $2 \%$ BSA and $0.5 \%$ Triton. Goat anti-rabbit CY.3-labeled IgG (Molecular Probes, Leiden, The Netherlands) was used as secondary antibody (1:400 dilution, $1 \mathrm{~h}$, room temperature). Plant nuclei and bacteroids were stained with SYTOX (Molecular Probes). For IAA immunolocalization, nodules were prefixed under a brief vacuum treatment in freshly prepared 4\% (wt/vol) 1-ethyl-3-(3-dimethyl-aminopropyl)-carbodiimide hydrochloride (EDAC) (Sigma) in $0.1 \times$ PBS, $\mathrm{pH}$ 7, at room temperature for $30 \mathrm{~min}$. EDAC cross-links IAA to structural proteins (Shi et al. 1993). Subsequently, nodules were postfixed in $4 \%$ paraformaldehyde in cacodylate buffer, $\mathrm{pH} 7.4$, containing $25 \mathrm{mg}$ of sucrose per $\mathrm{ml}$ (40 min at room temperature under vacuum). Nodule sections were incubated for $30 \mathrm{~min}$ in a blocking solution of $5 \%$ goat normal serum (Sigma) in PBS and were incubated overnight at $4^{\circ} \mathrm{C}$ with the primary antibody. A mouse monoclonal hybridoma antibody raised against IAA-BSA conjugate (IAA-17-II-A) (Agdia-Phytodetek/Linaris, Elkhart, IN, U.S.A.) was used at a concentration of $1 \mu \mathrm{g} / \mu \mathrm{l}$. Goat anti-mouse Alexa 488-labeled IgG (Molecular Probes) was used as secondary antibody (1:100 dilution, $2 \mathrm{~h}$, room temperature). Sections were counterstained with propidium iodide. Controls were carried out in the absence of primary antibodies. Sections were embedded in Fluoromount G (Electron Microscopy Sciences, Ft. Washington, PA, U.S.A.) and were examined using a Leits DM IRB inverted epifluorescence microscope connected to a Leica TCS 4D confocal system (Bannockburn, IL, U.S.A.).

\section{RT-PCR.}

Total RNA was isolated from $100 \mathrm{mg}$ of tissue, using the RNeasy plant mini kit (Qiagen, Hilden, Germany), and was treated with RNase-free DNase I (Qiagen), to remove any genomic DNA contamination, according to the manufacturer's recommendations. RNA $(1 \mu \mathrm{g})$ was reverse-transcribed into single-stranded cDNA templates using the First-strand cDNA synthesis kit (Roche, Mannheim, Germany).

Consensus primers were designed from the alignment of highly conserved sequence regions of $\mathrm{AO}$ or ubiquitin genes. Primers were used to amplify L. albus and M. truncatula nodule cDNA. The amplified PCR products were cloned into a pDRIVE plasmid (Qiagen), using the PCR cloning kit (Qiagen) following, the manufacturer's protocol. Sequence analyses confirmed high homologies (over 85\%) with other published plant $\mathrm{AO}$ and ubiquitin sequences. Primers were designed based on the sequence of L. albus cDNAs. The specific primers designed to amplify L. albus AO (forward primer, 5'GAGTCAAGCTGTGAAGCAGTTAGGC-3' and reverse primer, 5'-CTAACCCCATGACAAAACCTCCTTC-3') generated a 343-bp PCR product. The specific primers designed to amplify L. albus ubiquitin (forward primer, 5'-CACTGGGAAGACCA TTACTCTTGAGG-3' and reverse primer, 5'-TAGTCAGCGA GAGTCCTTCCATCTTC-3') generated a 153-bp PCR product.

\section{In situ hybridization.}

Antisense $\left[{ }^{35} \mathrm{~S}\right]$ RNA probes and sense $\left[{ }^{35} \mathrm{~S}\right]$ RNA control probes were generated by in vitro transcription with $\mathrm{T} 7$ and SP6 RNA polymerases (Stratagene, La Jolla, CA, U.S.A.), respectively, as described by the manufacturer, using pDRIVEcloned AO partial cDNA clones as templates. After phenol extraction and ethanol precipitation, riboprobes were separated 
from free $\left[{ }^{35} \mathrm{~S}\right]$ uridine triphosphate with a Sephadex G-50 column (Amersham Pharmacia Biotech, Piscataway, NJ, U.S.A). Probes were partially degraded to a length of approximately 150 nucleotides by heating at $60^{\circ} \mathrm{C}$ for $36 \mathrm{~min}$, in a $60 \mathrm{mM}$ $\mathrm{Na}_{2} \mathrm{CO}_{3} / 40 \mathrm{mM} \mathrm{NaHCO}$ solution.

In situ hybridization was performed according to Scheres and associates (1990). Nodules were fixed in $4 \%$ paraformaldehyde in $0.01 \mathrm{M}$ phosphate buffer overnight. Material was dehydrated in ethanol series and was left in $100 \%$ ethanol for 3 h. Ethanol was subsequently replaced with xylene. Nodules were embedded in Paraplast (Sigma). Sections $(7 \mu \mathrm{m})$ were cut with a microtome Spencer 820 (American Optical Corporation). Prior to hybridization paraffin was removed in a xyleneethanol series. Prehybridization included incubation of the slides at $37^{\circ} \mathrm{C}$ for $30 \mathrm{~min}$ in Proteinase $\mathrm{K}(1 \mu \mathrm{g} / \mathrm{ml})$ (Sigma) in $100 \mathrm{mM}$ Tris- $\mathrm{HCl}$ (pH 7.5), 50 mM EDTA. The hybridization mix contained $50 \%$ formamide, $300 \mathrm{mM} \mathrm{NaCl}, 10 \mathrm{mM}$ Tris$\mathrm{HCl}(\mathrm{pH} 7.5), 1 \mathrm{mM}$ EDTA, $0.02 \%$ polyvinylpyrrolidon, $10 \%$ dextran sulphate, $60 \mathrm{mM}$ DTT, and yeast tRNA $(150 \mu \mathrm{g} / \mathrm{ml})$. A total of $150 \mu \mathrm{l}$ of hybridization solution was used per slide. Slides were covered with parafilm and were incubated at $42^{\circ} \mathrm{C}$ overnight in a moisture chamber, then were washed, dehydrated, and dipped in Amersham nuclear-track (LM-1) emulsion. Slides were developed using a D-19 developer (Kodak) after 2 weeks of exposure, were contrasted with $0.5 \%$ eosin, and were photographed.

\section{ACKNOWLEDGMENTS}

The authors thank T. Bisseling and R. Mirabella for help with radioactive in situ hybridization, H. P. Spaink for providing Mesorhizobium loti NZP2037, F. Temprano for his information on lupin nodulation by M. loti, and G. E. Welbaum for providing anti-ABA antibodies. We also thank C. Bailón and M. C. Hernández from the Instituto de Neurobiología Ramón y Cajal, Consejo Superior de Investigaciones Científicas for technical assistance with the laser confocal microscope. We thank W. Sanders for revising the manuscript. This work was supported by grants BIO2001-2355 and AGL2001-2093 from the Ministerio de Ciencia y Tecnología (MCYT) (Spain). E. Federova was a recipient of a MCYT sabbatical contract.

\section{LITERATURE CITED}

Akaba, S., Seo, M., Dohmae, N., Takio, K., Sekimoto, H., Kamiya, Y., Furuya, N., Komano, T., and Koshiba, T. 1999. Production of homoand hetero-dimeric isozymes from two aldehyde oxidase genes of Arabidopsis thaliana. Plant Cell Physiol. 39:433-442.

Aloni, R., Schwalm, K., Langhans, M., and Ullrich, C. I. 2003. Gradual shifts in sites of free-auxin production during leaf-primordium development and their role in vascular differentiation and leaf morphogenesis in Arabidopsis. Planta 216:841-853.

Bartel, B. 1997. Auxin biosynthesis. Annu. Rev. Plant Physiol. Plant Mol. Biol.48:51-66.

Boot, K. J. M., van Brussel, A. A. N., Tak, T., Spaink, H. P., and Kijne, J. W. 1999. Lipochitin oligosaccarides from Rhizobium leguminosarum bv. viciae reduce auxin transport capacity in Vicia sativa subsp. nigra roots. Mol. Plant-Microbe Interact. 12:839-844.

Cooper, J. B., and Long, S. R. 1994. Morphogenetic rescue of Rhizobium meliloti nodulation mutants by trans-zeatin secretion. Plant Cell 6:215225 .

de Billy, F., Grosjean, C., May, S., Bennett, M., and Cullimore, J. V. 2001. Expression studies on AUX1-like genes in Medicago truncatula suggest that auxin is required at two steps in early nodule development. Mol. Plant-Microbe Interact. 14:267-277.

DeLong, A., Mockaitis, K., and Christensen, S. 2002. Protein phosphorylation in the delivery of and response to auxin signals. Pages 285-303 in: Auxin Molecular Biology. C. Perrot-Rechenmann and G. Hagen, eds. Kluwer Academic Publishers, Dordrecht, The Netherlands.

Fang, Y., and Hirsch, A. M. 1998. Studying early nodulin gene ENOD40 expression and induction by nodulation factor and cytokinin in alfalfa. Plant Physiol.116:53-68.

Fedorova, E. E., Greenwood, J. S., and G. S. Oaks A. 1994. In situ localization of nitrate reductase in maize root. Planta 194:279-286.

Fedorova, E. E., Zhiznevskaya, G. Y., Kalibernaya, Z. V., Artemenko, E.
N., Izmailow, S. F., and Gus'kov, A. 2000. IAA metabolism during the development of symbiosis between Phaseolus vulgaris and Rhizobium phaseoli. Russ. J. Plant Physiol. 47:203-206.

Ferguson, B. J., and Mathesius, U. 2003. Signaling interactions during nodule development. J. Plant Growth Regul. 22:47-72.

Fukuhara, H., Minakawa, Y., Akao, S., and Minamisawa, K. 1994. The involvement of indole-3-acetic acid produced by Bradyrhizobium elkanii in nodule formation. Plant Cell Physiol. 35:1261-1265.

González-Guzmán, M., Abia, D., Salinas, J., Serrano, R., and Rodríguez P. L. 2004. Two new alleles of abcisic aldehyde oxidase 3 gene reveal its role in abcisic acid biosynthesis in seeds. Plant Physiol. 135:325-333.

González-Sama, A., Lucas, M. M., de Felipe, M. R., and Pueyo, J. J. 2004. An unusual mechanism of infection and nodule morphogenesis in lupin (Lupinus albus) lead to a unique nodule type. New Phytol. 163:371380.

Heidstra, R., Yang, W. C., Yacin, Y., Peck, S., Emons, A., vanKammen, A., and Bisseling, T. 1997. Ethylene provides positional information on cortical cell division but is not involved in Nod factor-induced root hair tip growth in Rhizobium-legume interaction. Development 124:17811787.

Hirsch, A. 1992. Developmental biology of legume nodulation. New Phytol. 122:211-237.

Hirsch, A. M., Bhuvaneswari, T. V., Torrey, J. G., and Bisseling, T. 1989. Early nodulin genes are induced in alfalfa root outgrowths elicited by auxin transport inhibitors. Proc. Natl. Acad. Sci. U.S.A. 86:1244-1248.

Hirsch, A. M., Fang, Y., Asad, S., and Kapulnik, Y. 1997. The role of phytohormones in plant-microbe symbioses. Plant Soil 194:171-184.

Hoagland, D. R., and Arnon, D. I. 1938. The water culture method for growing plants without soil. University of California, Agricultural Experimental Station Circle. no. 347, Berkley, CA, U.S.A.

Jelenska, J., Deckert, J., Kondorosi, E., and Legocki, A. 2000. Mitotic Btype cyclins are differentially regulated by phytohormones and during yellow lupin nodule development. Plant Sci. 150:29-39.

Kawaguchi, M., and Syono, K. 1996. The excessive production of indole3 -acetic acid and its significance in studies of the biosynthesis of this regulator of plant growth and development. Plant Cell Physiol. 3:10431048 .

Kiers, T. E., Rousseau, R. A., West, S. A., and Denison, R. F. 2003. Host sanctions and the legume-Rhizobium mutualism. Nature 425:78-81.

Koiwai, H., Nakminami, K., Seo, M., Mitsuhashi, W., Toyomasu, T., and Koshiba, T. 2004. Tissue-specific localization of an abcisic acid biosynthetic enzyme, AAO3, in Arabidopsis. Plant Physiol. 134:1-11.

Koshiba, T., Saito, E., Ono, N., Yamamoto, N., and Sato, M. 1996. Purification and properties of flaying- and molybdenum-containing aldehyde oxidase from coleoptiles of maize. Plant Physiol. 110:781-789.

Lambrecht, M., Okon, Y., Vande Broek, A., and Vanderleyden, J. 2000. Indole-3-acetic acid: A reciprocal signaling molecule in bacteria-plant interactions. Trends Microbiol. 8:298-300.

Ljung, K., Hull, A. K., Kowalczyk, M., Marchant, A., Celenza, J., Cohen, J. D., and Sandberg, G. 2002. Biosynthesis, conjugation, catabolism and homeostasis of indole-3-acetic acid in Arabidopsis thaliana. Pages 249-272 in: Auxin Molecular Biology. C. Perrot-Rechenmann and G. Hagen, eds. Kluwer Academic Publishers, Dordrecht, The Netherlands.

Lohar, D. P., Schaff, J. E., Laskey, J. G., Kieber, J. J., Bilyeu, K. D., and Bird, D. M. 2004. Cytokinins play opposite roles in lateral root formation, and nematode and Rhizobial symbioses. Plant J. 38:203-214.

Long, S. R. 1996. Rhizobium symbiosis: Nod factors in perspective. Plant Cell 8:1885-1898.

Mathesius, U. 2001. Flavonoids induced in cells undergoing nodule organogenesis in white clover are regulators of auxin breakdown by peroxidase. J. Exp. Bot. 52:419-426.

Mathesius, U., Schlaman, H. M., Spaink, H. P., Sautter, C., Rolfe, B. G., and Djordjevic, M. A. 1998. Auxin transport inhibition precedes root nodule formation in white clover roots and is regulated by flavonoids and derivates of chitin oligosaccarides. Plant J. 14:23-34.

Mathesius, U., Charon, C., Rolfe, B. G., Kondorosi, A., and Crespi, M. 2000. Temporal and spatial order of events during the induction of cortical cell divisions in white clover by Rhizobium leguminosarum bv. trifolii inoculation or localized cytokinin addition. Mol. Plant-Microbe Interact. 13:617-628.

Miyata, S., Suzuki, Y., Kamisaka, S., and Masuda, Y. 1981. Indole -3acetaldehyde oxidase of pea seedlings. Physiol. Plantarum. 51:402-406.

Normanly, J., and Bartel, B. 1999. Redundancy as a way of life-IAA metabolism. Curr. Opin. Plant Biol. 2:207-213.

Ohmiya, A., Haayashi, T., and Kakiuchi, N. 1990. Immuno-gold localization of indole-3-acetic acid in peach seedlings. Plant Cell Physiol. 31:711-715.

Oldroyd, G. E. D., Engstrom, E. M., and Long, S. R. 2001. Ethylene inhibits the Nod Factor signal transduction pathway of Medicago truncatula. Plant Cell 13:1835-1849. 
Omarov, R., Dräger, D., Tischner, R., and Lips, H. 2003. Adlehyde oxidase isoforms and subunit composition in roots of barley as affected by ammonium and nitrate. Physiol Plantarum 117:337-342.

Pastor, A., López-Carbonell, M. and Alegre, L. 1999. Abcisic acid immunolocalization and ultrastructural changes in water-stressed lavender (Lavandula stoechas L.) plants. Physiol. Plant. 105:272-279.

Roudier, F., Fedorova, E., Lebris, M., Lecomte, P., Györgiev, J., Vaubert, D., Horvath, G., Abad, P., Kondorosi, A., and Kondorosi, E. 2003. The Medicago species A2-type cyclin is auxin regulated and involved in meristem formation but dispensable for endoreduplication-associated developmental programs. Plant Physiol. 131:1091-1103.

Scheres, B., van Engelen, F., van der Knaap, E., van de Wiel, C., van Kammen, A., and Bisseling, T. 1990. Sequential induction of nodulin gene expression in the developing pea nodule. Plant Cell. 2:687-700.

Schultze, M., and Kondorosi, A. 1998. Regulation of symbiotic root nodule development. Annu. Rev. Genet. 32:33-57.

Sekimoto, H., Seo, M., Dohmaei, N., Takioi, K., Kamiya, Y., and Koshiba, T. 1997.Cloning and molecular characterization of plant aldehyde oxidase. J. Biol. Chem. 272:15280-15285.

Sekimoto, H, Seo, M, Kawakami, N, Komano, T, Desloire, S, Liotenberg, S, Marion-Poll, A, Caboche, M, Kamiya, Y, and Koshiba, T. 1998. Molecular cloning and characterization of aldehyde oxidases in Arabidopsis thaliana. Plant Cell Physiol. 39:33-42.

Seo, M., and Koshiba, T. 2002. Complex regulation of ABA biosynthesis in plants. Trends Plant Sci. 7:41-48.

Seo, M., Akaba, S., Oritani, T., Delarue, M., Bellini, C., Caboche, M., and T. Koshiba. 1998. Higher activity of an aldehyde oxidase in the auxinoverproducing superroot 1 mutant of Arabidopsis thaliana. Plant Physiol.116:687-693.

Seo, M., Koiwai, H., Akaba, S., Komano, T., Oritani, T., Kamiya, Y., and Koshiba, T. 2000a. Abscisic aldehyde oxidase in leaves of Arabidopsis thaliana. Plant J. 23:481-488.

Seo, M., Peeters, A. J .M., Koiwai, H., Oritani, T., Marion-Poll, A., Zeevaart, J. A. D., Koornneef, M., Kamiya, Y., and Koshiba, T. 2000b. The Arabidopsis aldehyde oxidase 3 (AAO3) gene product catalyzes the final step in abcisic acid biosynthesis in leaves. Proc. Natl. Acad. Sci. U.S.A. 97:12908-12913.

Shi, L., Miller, I., and Moore, R. 1993. Immunocytochemical localization of indole-3-acetic acid in primary roots of Zea mays. Plant Cell Environ. 16:967-973.

Stals, H., and Inze, D. 2001. When plant cells decide to divide. Trends Plant Sci. 6:359-364.

Stougaard, J. 2000. Regulators and regulation of legume root nodule development. Plant Physiol. 124:531-540.

Thomas, C., Bronner, R., Molinier, J., Prinsen, E., van Onckelen, H., and Hahne, G. 2002. Immuno-cytochemical localization of indole-3-acetic acid during induction of somatic embryogenesis in cultured sunflower embryos. Planta 215:577-583.

Varma, R., Penmetsa, J. A., Frugoli, L., Smith, S., Long, S. R., and Cook, D. R.. 2003. Dual genetic pathways controlling nodule number in Medicago truncatula. Plant Physiol. 131:998-1008.

Vasse, J., de Billy, F., Camut, S., and Truchet, G. 1990. Correlation between ultrastructural differentiation of bacteroids and nitrogen fixation in alfalfa nodules. J. Bacteriol. 172:4295-4306.

Vincent, J. M. 1970. A manual for the practical study of root-nodule bacteria. I.B.P. Handbook no. 15. Blackwell Scientific Publications, Oxford.

Welbaum, G. E., Bian, D., Hill, D. R., Grayson, R. L., and Gunatilaka, M. K. 1997. Freezing tolerance, protein composition, and abscisic acid localization and content of pea epicotyl, shoot, and root tissue in response to temperature and water stress. J. Exp. Bot. 48:643-654.

Zdunek E., and Lips, S. H. 2001. Transport and accumulation rates of abcisic acid and aldehyde oxidase activity in Pisum sativum L. in response to suboptimal growth conditions. J. Exp. Bot. 52:1-8.

Zdunek-Zastocka, E., Omarov, R. T., Koshiba, T., and Lips, S. H. 2004. Activity and protein level of AO isoforms in pea plants (Pisum sativum L.) during vegetative development and in response to stress conditions. J. Exp. Bot. DOI: 10.1093/jxb/erh134, 1-9.

Zhu, J., Oger, P. M., Schrammeijer, B., Hooykaas, P. J. J., Farrand, S. K., and Winans, S. C. 2000. The bases of crown gall tumorigenesis. J. Bacteriol. 182:3885-3895. 